\title{
EpCAM is overexpressed in local and metastatic prostate cancer, suppressed by chemotherapy and modulated by MET-associated miRNA-200c/205
}

\author{
P Massoner ${ }^{\star}, 1,2$, T Thomm² ${ }^{2}$ B Mack ${ }^{2}$, G Untergasser ${ }^{3}$, A Martowicz $^{3}$, K Bobowski $^{2}$, H Klocker ${ }^{1}$, O Gires $^{\star}, 2,4$ \\ and M Puhr ${ }^{1,4}$ \\ ${ }^{1}$ Experimental Urology, Department of Urology, Innsbruck Medical University, Innsbruck, Austria; ${ }^{2}$ Department of Otorhinolar- \\ yngology, Head and Neck Surgery, Ludwig-Maximilians-University, Munich, Germany and ${ }^{3}$ Laboratory of Experimental Oncology, \\ Tyrolean Cancer Research Institute, Innsbruck, Austria
}

Background: Expression of epithelial cell adhesion molecule (EpCAM) is deregulated in epithelial malignancies. Beside its role in cell adhesion, EpCAM acts as signalling molecule with tumour-promoting functions. Thus, EpCAM is part of the molecular network of oncogenic receptors and considered an interesting therapeutic target.

Methods: Here, we thoroughly characterised EpCAM expression on mRNA and protein level in comprehensive tissue studies including non-cancerous prostate specimens, primary tumours of different grades and stages, metastatic lesions, and therapytreated tumour specimens, as well as in prostate cancer cell lines.

Results: Epithelial cell adhesion molecule was overexpressed at mRNA and at protein level in prostate cancer tissues and cell lines. Altered EpCAM expression was an early event in prostate carcinogenesis with an upregulation in low-grade cancers and further induction in high-grade tumours and metastatic lesions. Interestingly, EpCAM was repressed upon induction of epithelialto-mesenchymal transition (EMT) following chemotherapeutic treatment with docetaxel. Oppositely, re-induction of the epithelial phenotype through miRNAs miR-200c and miR-205, two inducers of mesenchymal-to-epithelial transition (MET), led to reinduction of EpCAM in chemoresistant cells. Furthermore, we prove that EpCAM cleavage, the first step of EpCAM signalling takes place in prostate cancer cells but in contrast to other cancer entities, EpCAM has no measurable impact on the proliferative behaviour of prostate cells, in vitro.

Conclusions: In conclusion, our data confirm that EpCAM overexpression is an early event during prostate cancer progression. Epithelial cell adhesion molecule displays a dynamic, heterogeneous expression and associates with epithelial cells rather than mesenchymal, chemoresistant cells along with processes of EMT and MET.

Hallmarks of cancer are limitless replication of tumour cells, their highly proliferative phenotype and their ability to metastasise (Hanahan and Weinberg, 2000). How tumourpromoting stimuli are achieved can vary among tumour types and between individual tumours. Some features like the pathologic deregulation of oncogenic receptors and signalling proteins, which often turns them into highly overexpressed, ligand-independent and/or permanently active molecules are, however, common for all malignancies, including prostate cancer (PCa).

\footnotetext{
*Correspondence: Dr P Massoner; E-mail: Petra.Massoner@i-med.ac.at or Professor O Gires; E-mail: Olivier.Gires@med.uni-muenchen.de ${ }^{4}$ These authors contributed equally to this work.
} 
One example of such receptors is the epithelial cell adhesion molecule (EpCAM), which is known to be deregulated in a variety of carcinomas (Went et al, 2006; Baeuerle and Gires, 2007; Trzpis et al, 2007). Epithelial cell adhesion molecule is a type I transmembrane glycoprotein of 314 amino acids (aa), consisting of a 23-aa signal peptide, a large extracellular domain (N-terminal) of 242 aa, a single-spanning transmembrane domain of 23 aa and a short cytoplasmic domain of 26 aa (C-terminal; Strnad et al, 1989). Epithelial cell adhesion molecule is specifically expressed in normal epithelia where it is co-localised with E-cadherin and claudins at basolateral membranes and tight-junction (Moldenhauer et al, 1987; Balzar et al, 1999; Wu et al, 2013). Therefore, EpCAM is considered a marker for an epithelial phenotype.

Over a long time EpCAM functions were thought to be limited to its actions as cell surface and adhesion molecule. During the last years, additional EpCAM functions as signalling molecule emerged (Maetzel et al, 2009). Epithelial cell adhesion molecule signalling is activated upon regulated intramembrane proteolysis (RIP) and subsequent release of the intracellular domain EpICD, which associates with components of the Wnt pathway (FHL2, $\beta$-catenin, Lef- 1 ), translocates to the nucleus, and functions as transcription regulator. Epithelial cell adhesion molecule induced genes, such as $c$-myc, cyclin D1, mmp7 (Munz et al, 2004; Maetzel et al, 2009; Denzel et al, 2009; Chaves-Perez et al, 2012), and regulators of the cell cycle and proliferation machinery, in general (Maaser and Borlak, 2008). In this context, increased EpCAM expression was shown to correlate with elevated proliferation, with cancer development and progression, and with decreased overall survival of cancer patients (Gastl et al, 2000; Piyathilake et al, 2000; Munz et al, 2004; Osta et al, 2004; Baeuerle and Gires, 2007; van der Gun et al, 2011). Thus, EpCAM nowadays needs to be considered in the molecular network of oncogenic receptors and represents a promising target for new therapeutic approaches in numerous carcinomas.

To address the question whether EpCAM is a promising target for improved PCa therapy, we have conducted a detailed study on EpCAM mRNA and protein expression, which is characterised by high sample numbers, several independent analyses, and inclusion of tissues and cell lines representing a variety of different stages and grades of PCa. Our study is complemented by findings that EpCAM expression is reduced after epithelial-to-mesenchymal transition (EMT) upon chemotherapeutic treatment, whereas mesenchymal-to-epithelial transition (MET) inducing miRNA200c and miRNA-205 reinduced expression of EpCAM. Furthermore, we prove that EpCAM cleavage takes place in $\mathrm{PCa}$, but in contrast to other cancer entities, EpCAM has no measurable impact on proliferation of prostate cells, in vitro.

\section{MATERIALS AND METHODS}

Databases and meta-analysis data. To get an overview on EpCAM expression we made queries using the database Oncomine (www.oncomine.com; Rhodes et al, 2004). Furthermore, we analysed data of a PCa meta-analysis study which we performed previously (Massoner et al, 2013).

Tissue samples. Tissue samples were selected from the Innsbruck PCa biobank (Innsbruck, Austria). This biobank was established in the course of the Tyrolean early detection programme for PCa at the Department of Urology, Innsbruck Medical University (Bartsch et al, 2008). Written consent was obtained from all patients and documented in the database of the University Hospital Innsbruck in agreement with statutory provisions and the requirements of the Ethics Committee of the Innsbruck Medical University. The study was approved by the Ethics Committee of the Innsbruck Medical University (Study no. AM 3174 and amendment 2).
Tissue microarrays (TMAs) containing benign and primary cancer tissue cores from $90 \mathrm{PCa}$ patients who underwent radical prostatectomy at the University Hospital Innsbruck and metastatic tissue cores from $16 \mathrm{PCa}$ patients were analysed to evaluate EpCAM expression during $\mathrm{PCa}$ progression. Furthermore, to assess consequences of the chemotherapeutic drug docetaxel on EpCAM expression a TMA containing tissue blocks of $14 \mathrm{PCa}$ patients who underwent neoadjuvant chemotherapy with docetaxel before radical prostatectomy and 14 untreated PCa patients was investigated (Puhr et al, 2012).

Immunohistochemistry. Antigen retrieval and immunohistochemistry were performed using a Discovery XT automated slide-staining system (Ventana Medical Systems, Ventana, Tucson, AZ, USA). Antigen retrieval was performed by heat pretreatment at $98^{\circ} \mathrm{C}$ for $1 \mathrm{~h}$ in CC1 buffer (Ventana Medical Systems). Anti-EpCAM antibody $(1: 50$, clone VU-1D, Novocastra, Milton Keynes, UK) and anti-p63 antibody $(1: 100$, Sigma-Aldrich, St Louis, MO, USA) were incubated for $1 \mathrm{~h}$ at $37^{\circ} \mathrm{C}$, followed by iView DAB detection (diaminobenzidine visualisation, Ventana Medical Systems) and haematoxylin counterstaining. Microscope pictures were taken with a Zeiss Imager Z2 microscope (Zeiss, Vienna, Austria) using TissueFAXS software (Tissue Gnostics, Vienna, Austria). Immunohistochemical evaluation was done using the semiquantitative scoring system 'quick score' calculating an immunoreactivity staining (IRS) score combining the proportion of positive cells and the average staining intensity (Detre et al, 1995).

Cell lines and culture. Human PCa cell lines Du145, DuCaP, LNCaP and PC3 were cultured in RPMI 1640 supplemented with $10 \%$ fetal calf serum and $1 \%$ penicillin/streptomycin glutamine. The non-cancerous cell lines EP156T and RWPE-1 were cultured as previously described (Bello et al, 1997; Kogan et al, 2006). Docetaxel-resistant PC3-DR and Du-145-DR cells were cultured in the presence of $12.5 \mathrm{~nm}$ docetaxel (Sigma-Aldrich) as previously described (Puhr et al, 2012). The identity of all cell lines was confirmed by short tandem repeat analysis. Cell proliferation was assessed by counting total cell numbers.

siRNA, shRNA and miRNA transfection. Transient EpCAM knockdown was achieved by siRNA transfection ( $50 \mathrm{~nm}$ ) for $72 \mathrm{~h}$ using lipofectamine transfection reagent (Invitrogen, Carlsbad, CA, USA). Sequences: EpCAM siRNA, 5'-UGCCAGUGUACUUCA GUUG-3'; control siRNA, 5'-UCGUCCGUAUCAUUUCAAU-3'. Stable EpCAM knockdown was achieved by stable shRNA expression introduced by lentiviral pGIPZ vectors (Thermo Scientific, Rockford, IL, USA) followed by puromycine selection as previously described (Ploner et al, 2008; Martowicz et al, 2012). For miRNA transfection, hsa-miR-200c, hsa-miR-205, and miRNA mimic negative control were purchased from Dharmacon (Chicago, IL, USA). Cells were transfected twice during a period of 6 days with $25 \mathrm{~nm}$ miRNAs using lipofectamine transfection reagent (Invitrogen).

RNA isolation, cDNA synthesis and qRT-PCR. RNA isolation and cDNA synthesis was performed using the RNeasy mini kit (Qiagen, Hilden, Germany) and iScript select cDNA synthesis kit (Bio-Rad, Hercules, CA, USA) following the manufacturers protocols. qRT-PCR was carried out on a ABI Prism 7500 Fast RT-PCR System (Life Technologies, Carlsbad, CA, USA) or a LightCycler 480II (Roche Applied Science, Basel, Switzerland) instrument. Primer and probe sequences for TBP and HPRT1 (endogenous controls) were as follows: TBP (forward $5^{\prime}$-CACG AACCACGGCACTGATT- ${ }^{\prime}$; reverse $5^{\prime}$-TTTTCTGCTGCCAGTC TGGAC-3'; probe $5^{\prime}$-FAM-TCTTCACTCTTGGCTCCTGTGC ACA-TAMRA-3'), HPRT1 (forward primer, 5'-GCTTTCC TTGGTCAGGCAGTA- ${ }^{\prime}$; reverse $5^{\prime}$-GTCTGGCTTATATCCAA CACTTCGT-3'; probe, 5'-FAM-GTCTGGCTTATATCCAAC 
ACTTCGT-TAMRA-3'). For EpCAM a Taqman gene expression assay (Hs00158980_m1) was used.

Membrane enrichment assay and immunoblot. Membrane enrichment assay was performed as previously described (Sastre et al, 2001). In short, cells were seeded on petri discs and left untreated or treated with $1 \mu \mathrm{M}$ of the $\gamma$-secretase inhibitor DAPT (Sigma-Aldrich) for $24 \mathrm{~h}$. At $80 \%$ confluence and $4 \mathrm{~h}$ prior harvesting the cells were treated with the proteasome inhibitor MG-132 (10 $\mu \mathrm{M}$, Sigma-Aldrich), placed on ice and washed in icecold PBS. All following steps were performed on ice using ice-cold solutions. Cells were harvested by scraping, centrifuged, washed trice with PBS, homogenised in homogenisation buffer $(10 \mathrm{~mm}$ MOPS, $10 \mathrm{~mm} \mathrm{KCl}$ and protease inhibitors) and dounced using a 23 -gouge needle. Cell membranes were pelleted at $16000 \mathrm{~g}$. The pellet containing enriched cell membranes was dissolved in assay buffer (150 mM sodium citrate, $10 \mu \mathrm{M} \mathrm{ZnCl}_{2}, 1 \mu \mathrm{g} \mathrm{ml}{ }^{-1}$ phorbol12-myristate 13 -acetate and protease inhibitors) and incubated at $37^{\circ} \mathrm{C}$ or on ice.

Approximately, $5 \mu \mathrm{g}$ enriched cell membranes or $50 \mu \mathrm{g}$ total proteins per lane were resolved in an SDS-PAGE and transferred onto a nitrocellulose membrane (Invitrogen). The membrane was blocked for $1 \mathrm{~h}$ using Starting Block buffer (Pierce Biotechnology, Rockford, IL, USA) and incubated at $4{ }^{\circ} \mathrm{C}$ overnight with a primary antibody followed by incubation for $1 \mathrm{~h}$ at room temperature with secondary antibodies. The following antibodies were used for western blots: anti-GAPDH $(1: 100000$, Chemicon, Vienna, Austria), anti-EpCAM (1:1000; clone VU-1D, Novocastra), antiEpCAM (1:1000, clone C10, Santa Cruz Biotechnology (Santa Cruz, CA, USA) = anti-EpEX) and anti-EpCAM (1:5000, polyclonal guinea pig, peptide specific laboratories = anti-EpICD), and anti-GFP (1:500, clone B-2, Santa Cruz Biotechnology).
Immunocytological fluorescent staining and laser scanning microscopy. Cells were seeded on object slides and fixed using paraformaldehyde and methanol as previously described (Brock et al, 1999). Blocking was performed at room temperature for $30 \mathrm{~min}$ using normal goat serum. Primary antibodies were incubated overnight at $4^{\circ} \mathrm{C}$, while Alexa-labeled secondary antibodies (Molecular Probes, Carlsbad, CA, USA) were incubated for $1 \mathrm{~h}$ at room temperature. Antibodies used were anti-EpCAM $(1: 1000$, clone C10, Santa Cruz Biotechnology $=$ anti-EpEX) and anti-EpCAM $(1: 500$, polyclonal guinea pig, peptide specific laboratories $=$ anti-EpICD). Pictures were analysed in a fluorescence laser scanning system (TCS-SP2 scanning system and DM IRB inverted microscope, Leica, Wetzlar, Germany).

Statistics. Statistical analysis was performed with GraphPad Prism 5.0 (GraphPad Software, Inc., La Jolla, CA, USA) and SPSS 15.0 software (IBM SPSS Statistics, IBM, Ehningen, Germany). For all experiments Gaussian distribution was determined using Kolmogorov-Smirnov test. Differences between treatment groups were analysed either using Student's $t$-test or Mann-Whitney $U$ test. $P$ values below 0.05 were considered significant. All differences highlighted by asterisks were statistically significant and encoded in figures $\left({ }^{\star} P<0.05,{ }^{*} P<0.01\right.$ and $\left.{ }^{* *} P<0.001\right)$. Data are presented as mean + s.d. of a minimum of three independent experiments unless otherwise stated.

\section{RESULTS}

EPCAM mRNA overexpression in PCa. In order to get an overview on EpCAM expression in cancer compared to normal tissues, we performed an Oncomine (Rhodes et al, 2004) query including data of 20 different cancer entities investigated in 183

\begin{tabular}{|c|c|c|}
\hline Cancer vs normal & $\begin{array}{c}\text { EpCAM } \\
\text { up-regulated }\end{array}$ & $\begin{array}{c}\text { EpCAM } \\
\text { down-regulated }\end{array}$ \\
\hline Bladder cancer & $2(5)$ * & \\
\hline Brain and CNS cancer & & $1(14)$ \\
\hline Breast cancer & $3(14)$ & \\
\hline Cervical cancer & $3(6)$ & \\
\hline Colorectal cancer & $1(13)$ & $1(13)$ \\
\hline Oesophageal cancer & $6(7)$ & \\
\hline Gastric cancer & $4(7)$ & \\
\hline Head and neck cancer & $3(18)$ & \\
\hline Kidney cancer & & $7(8)$ \\
\hline Leukemia & $1(11)$ & $3(11)$ \\
\hline Liver cancer & $4(7)$ & \\
\hline Lung cancer & $8(13)$ & \\
\hline \multicolumn{3}{|l|}{ Lymphoma } \\
\hline Melanoma & & $1(4)$ \\
\hline \multicolumn{3}{|l|}{ Myeloma } \\
\hline Other cancer & $2(15)$ & $1(15)$ \\
\hline Ovarian cancer & $6(8)$ & \\
\hline \multicolumn{3}{|l|}{ Pancreatic cancer } \\
\hline Prostate cancer & $9(16)$ & \\
\hline Sarcoma & & $3(6)$ \\
\hline Significant studies & 52 & 17 \\
\hline Included studies & & 72 \\
\hline
\end{tabular}

B

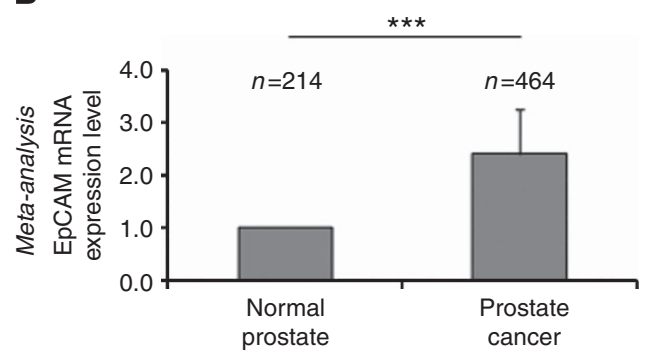

C

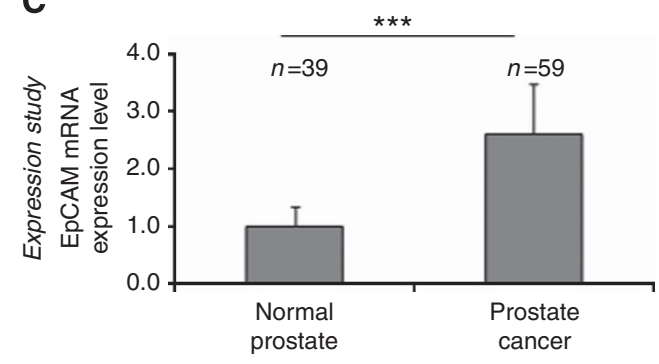

Figure 1. EpCAM mRNA expression is elevated in PCa. (A) EpCAM is overexpressed in a variety of human cancers. Oncomine query, status January 2014: number of datasets meeting the threshold $(P>0.001$, fold-change $>1.5)$ for EpCAM compared to total datasets are given. Outlier analysis revealed high variations of EpCAM expression in all analysed datasets. (B) Meta-analysis on published gene expression data identified a significantly increased EpCAM mRNA expression in PCa compared to normal prostate tissue. Meta-analysis was performed on 678 prostate tissue samples deriving from eight independent patient cohorts measured in eight different studies. EpCAM mRNA expression is significantly elevated in an independent expression analysis on 98 prostate tissues of the Innsbruck PCa biobank. Statistics were calculated using Fisher's combined Pvalue (B) and Mann-Whitney $U$ testing (C). ${ }^{\star \star \star} P<0.001$. 
studies (Figure 1A, number of significant datasets meeting the threshold $P<0.001$, fold-change $>1.5$ for EpCAM compared to total datasets). Epithelial cell adhesion molecule was overexpressed in several cancers compared to normal tissue (e.g., oesophageal, ovarian, lung and PCa). Some cancer entities were characterised by EpCAM downregulation including kidney cancer and sarcomas. Strikingly, EpCAM emerged in the Oncomine outlier analysis of almost every investigated study (www.oncomine.org; outlier analysis identifies genes regulated in a subset of samples thus reflecting expression heterogeneity), indicating that there is a high overall heterogeneity of EpCAM expression within and across tissues. To further evaluate EpCAM expression in $\mathrm{PCa}$, we extended our analysis to data from a meta-analysis study performed on published gene expression data of 678 prostate tissues measured on the Affymetrix (Santa Clara, CA, USA) platform in eight independent studies (Massoner et al, 2013; Figure 1B) and data of an independent expression study performed on 98 patients of the Innsbruck PCa biobank applying Illumina BeadChip arrays (Kuner et al, 2012; Figure 1C). In all studies, EpCAM was significantly elevated in PCa compared to benign, non-cancerous prostate tissue $(2.3 \pm 0.9$-fold elevated in $\mathrm{PCa}$, mean \pm s.d., $P<0.001)$. Different patient cohorts, diverse technologies and independent data analyses were combined in our approach and, therefore, we consider our data free of methodological or population-dependent bias.

EpCAM protein is overexpressed in PCa. We next extended our study to EpCAM protein data. In total, 179 prostate tissues from 104 patients were stained using immunohistochemistry. Epithelial cell adhesion molecule was overexpressed in malignant tissues compared to benign, non-cancerous prostate tissues (Figure 2A). Overexpression of EpCAM appeared more pronounced at protein level than at mRNA level $(4.2 \pm 2.1$-fold $v s 2.3 \pm 0.9$-fold overexpressed in PCa, protein vs mRNA level, respectively). Elevated expression of EpCAM was an early event in $\mathrm{PCa}$, which was detectable as early as in local low-grade cancer (Gleason score, GSC $\leqslant 7$ including GSC 7 with Gleason pattern $3+4$ ), in high-grade cancer (GSC $\geqslant 7$ including GSC 7 with Gleason pattern $4+3$ ) and in overt metastases (bone, $n=10$; lymph node, $n=6$ ). Epithelial cell adhesion molecule protein was increased in cancers of high GSC, in cancers of advanced stages and in metastases (Figure 2B$\mathrm{D})$, but remained unchanged in cancers harbouring ERG rearrangements (Tomlins et al, 2005) compared to ERG normal cancers (data not shown). Although we observed a further increase in expression of EpCAM in PCa metastases (Figure 2C), data need to be considered with caution since sample size was limited because metastases are not routinely surgically removed. We conclude from this study that EpCAM is overexpressed in local and metastatic $\mathrm{PCa}$, and induction of EpCAM expression is an early event in prostate carcinogenesis.

EpCAM overexpression is more pronounced at protein level. In our tissue analysis, we found EpCAM overexpression more pronounced at protein compared to mRNA level. Tissue mRNA data were mainly derived from array experiments performed on macro-dissected tissues containing proportions of non-epithelial cell types such as stromal, endothelial and immune cells. To discriminate whether the discrepancy between EpCAM mRNA and protein level is a true biologic difference or arises from tissue sample composition, we extended our analysis to in vitro cell culture models. We confirmed overexpression of EpCAM protein in PCa cell lines compared to non-cancerous prostate epithelial cells by immunoblot (total protein) and flow cytometry analyses (cell surface protein). Epithelial cell adhesion molecule cell surface levels were $16.7 \pm 8.8$-fold (mean \pm s.d.) elevated in PCa compared to non-cancerous prostate cell lines. Epithelial cell adhesion molecule mRNA levels determined by qRT-PCR $(2.5 \pm 2.8$-fold overexpression in $\mathrm{PCa}$ ), however, did not reflect the large differences observed on protein level (Figure 3A-D). In fact, the PCa cell lines LNCaP and PC3 express EpCAM mRNA levels
A

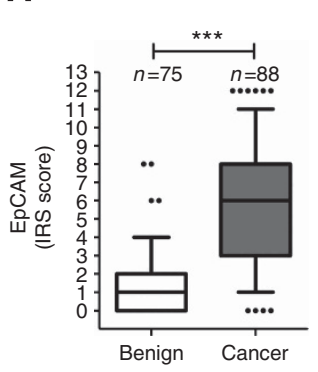

B

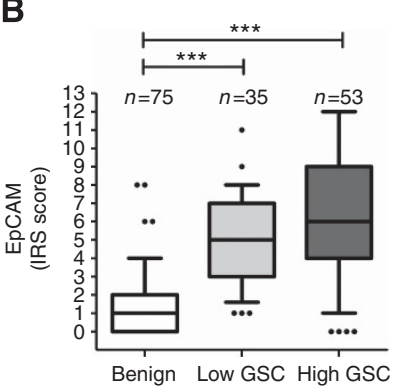

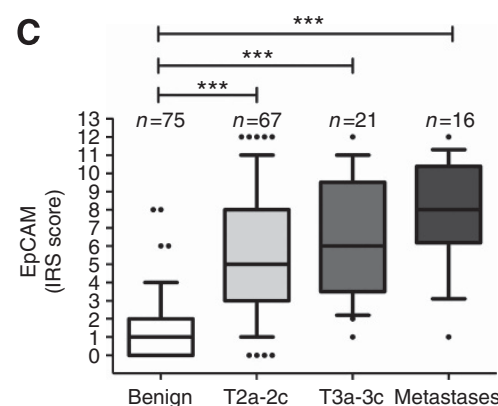

Metastases

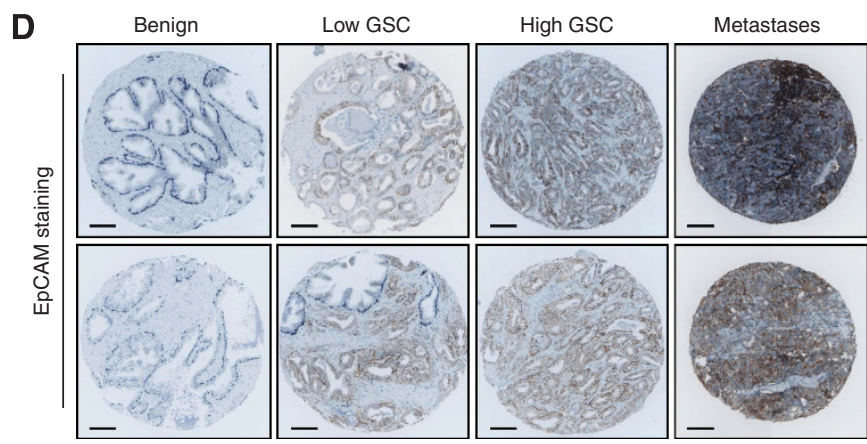

Figure 2. EpCAM protein is increased, expressed in primary and metastatic tissue of PCa patients. Statistical analyses of tissue microarrays reveal that EpCAM protein is significantly elevated in PCa compared to normal prostate tissue (A). EpCAM protein expression increases with Gleason score (GSC, B) and tumour stage (C) compared to normal prostate tissue. (D) Representative cores for benign, low GSC, high GSC, and metastatic prostate tissue. Co-staining of EpCAM (brown) and p63 (blue, marker for basal cells) ensured correct discrimination between benign and cancer glands. Semiquantitative analysis was performed applying quickscore criteria. Statistics were calculated using Mann-Whitney $U$ testing. $\star \star \star, P<0.001 ;$ bar, $100 \mu \mathrm{m}$. IRS, immunoreactivity staining score. 

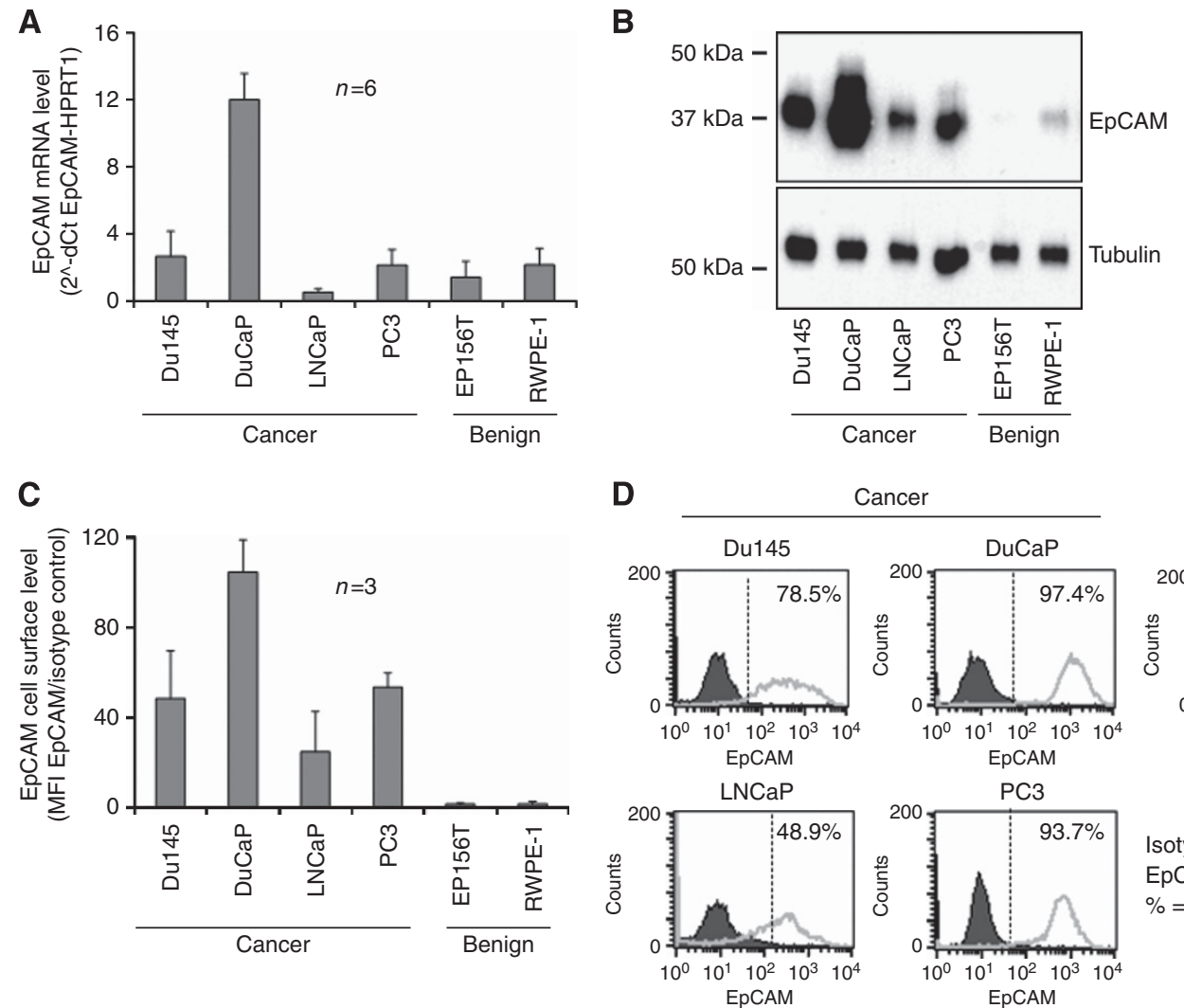

Cancer
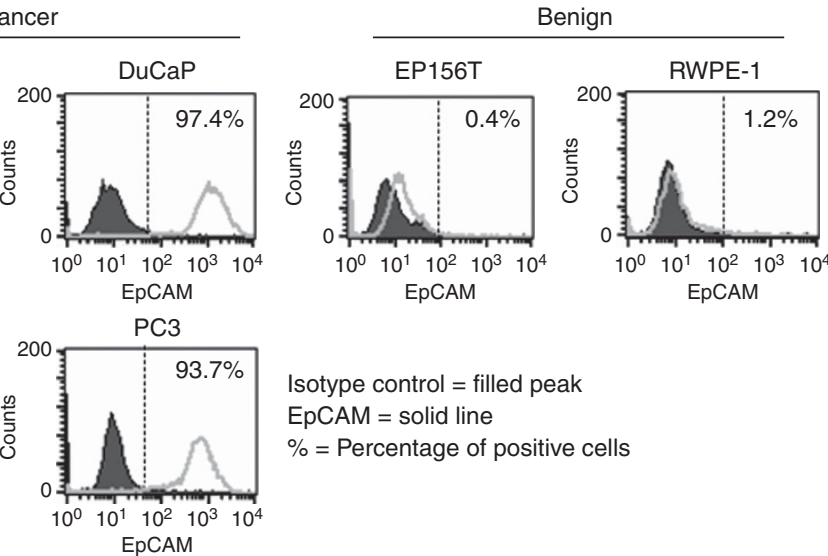

Isotype control = filled peak

EpCAM = solid line

$\%=$ Percentage of positive cells

Figure 3. EpCAM overexpression in PCa prevails at protein level. EpCAM mRNA expression levels were determined by qRT-PCR (A), EpCAM protein levels by immunoblot (B), and EpCAM cell surface protein levels by extracellular immunostaining and flow cytometry (C and D) in Du145, DuCaP, LNCaP, PC3, EP156T, and RWPE-1 cells.

comparable to non-cancerous cell lines EP156T and RWPE-1, whereas EpCAM protein levels in LNCaP and PC3 were clearly detectable by both immunoblot (total protein) and flow cytometry (cell surface protein), while at the detection limit in EP156T and RWPE-1 (Figure 3A-D). Thus, our data suggest that not only alterations in mRNA expression levels, but also changes in protein stabilities and protein turnover determine EpCAM expression levels in PCa.

EpCAM is cleaved to EpICD in PCa cells. Besides its role as an adhesion molecule, EpCAM functions as a signalling molecule and transcription regulator. This EpCAM function is based on RIP; Maetzel et al, 2009; Figure 4A). To study whether EpCAM exerts potential signalling functions in PCa, we investigated EpCAM RIP. Epithelial cell adhesion molecule is cleaved by proteases present in cell membranes (sheddases) from EpCAM full length (EpCAM-FL) to EpCAM C-terminal fragment (EpCAM-CTF), which is a substrate for $\gamma$-secretase that is further processed to the intracellular signalling molecule EpICD Maetzel et al, 2009; Figure 4A). To visualise EpCAM-FL, EpCAM-CFT and EpICD, we performed an immunoblot using antibodies, which selectively recognise the extracellular (anti-EpEX) or intracellular (antiEpICD) domain of EpCAM. Cell membranes of EpCAM-positive PCa cell lines were enriched as previously described (Hachmeister et al, 2013) and incubated at $4{ }^{\circ} \mathrm{C}$ and $37^{\circ} \mathrm{C}$ to repress or allow protease activity. In all four investigated PCa cell lines the first step of EpCAM cleavage (i.e., generation of EpCAM-CTF) was observed (Figure 4B). Visualisation of the second step of EpCAM cleavage (i.e., EpCAM-CTF to EpICD) is challenging in this setting because EpICD has a low apparent molecular weight of $5-6 \mathrm{kDa}$ and a short half-live owing to degradation by the proteasome (Hachmeister et al, 2013). To facilitate the detection of EpICD, we stabilised and enlarged EpICD by fusion to yellow fluorescence protein (YFP), as described (Maetzel et al, 2009; Hachmeister et al, 2013). In PCa cells overexpressing EpCAM-YFP, cleavage to EpCAM-YFP-CTF (first cleavage) and EpICD-YFP (second cleavage) was observed. Cleavage of EpCAM-CTF-YFP to EpICD-YFP was inhibited by DAPT, a chemical $\gamma$-secretase inhibitor (Figure 4C). Interestingly, also cells, which have very low endogenous EpCAM levels, such as the non-cancerous prostate cells RWPE-1, process EpCAM-YFP to EpICD-YFP, suggesting that the required processing machinery is present even in the absence of high levels of EpCAM protein. Next, EpCAM and its cleavage products were visualised using anti-EpEX and antiEpICD antibodies in immunofluorescence stainings. The antiEpEX antibody recognised full length EpCAM, localised at the membrane, while the anti-EpICD antibody recognised both, full length EpCAM localised at the cell membrane as well as cleaved EpICD in the cytoplasm (Figure 4D). Collectively these data reveal that EpCAM cleavage and generation of the intracellular signalling molecule EpICD is detectable in PCa cells, indicating that EpCAM $\mathrm{RIP}$ is active in PCa.

EpCAM has no effect on PCa cell proliferation in vitro. Epithelial cell adhesion molecule expression was reported to have a major impact on proliferation of cellular models deriving from several carcinoma entities including breast (Martowicz et al, 2012), colorectal (Maaser and Borlak, 2008), lung (Maaser and Borlak, 2008) and various forms of head and neck cancer (Maetzel et al, 2009; Chaves-Perez et al, 2012; Driemel et al, 2013). To test whether EpCAM has a proliferative effect also on PCa cells, we transiently or stably knocked down EpCAM by siRNA or shRNA, respectively. Epithelial cell adhesion molecule knockdown at mRNA and protein level was controlled by qRT-PCR and immunoblot (Figure 5A and 
A
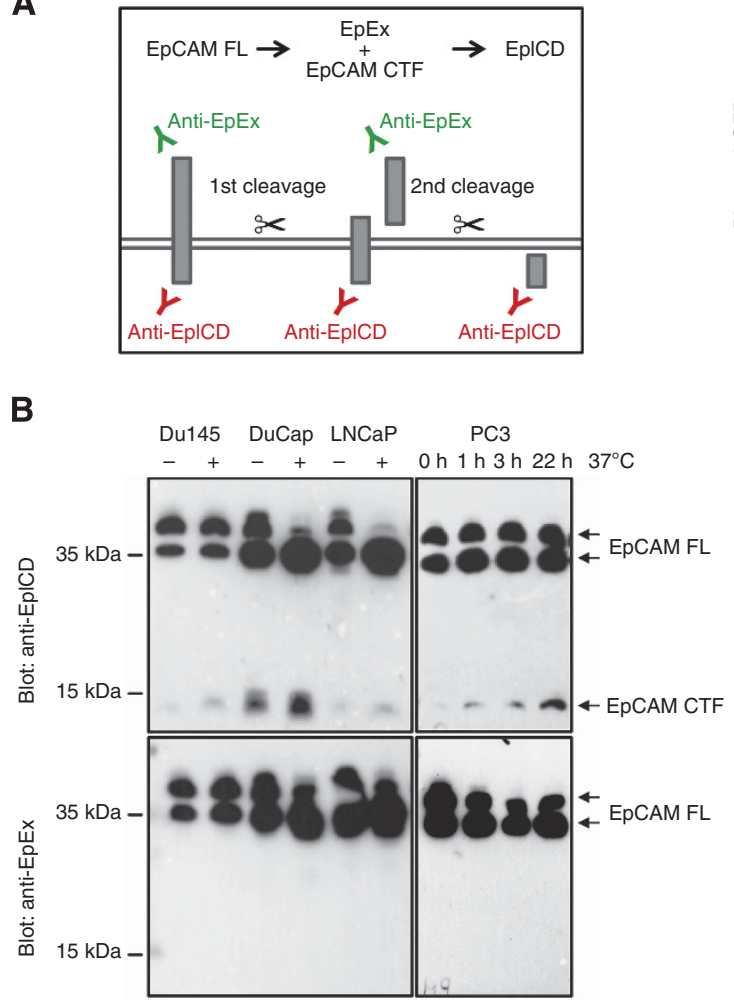

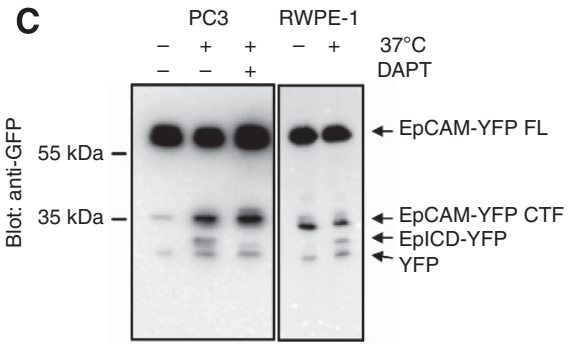

D

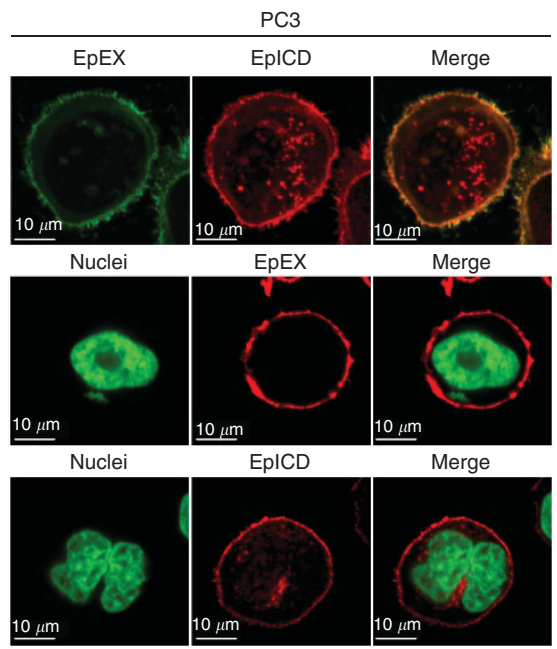

Figure 4. EpCAM cleavage in PCa. (A) Schematic representation of EpCAM cleavage. (B) Endogenous EpCAM is cleaved into EpCAM CTF in PCa cells. Membranes of prostate cancer cells were enriched by centrifugation and incubated at $37^{\circ} \mathrm{C}$ or on ice. EpCAM FL and EpCAM C-terminal fragment (CTF) were detected using an anti-EpICD antibody. EpCAM CTF was not detected by an anti-EpEX antibody (lower blot, negative control for EpCAM CTF). (C) EpCAM-YFP is cleaved to EpCAM-CTF-YFP and EpICD-YFP in PCa (PC3) and benign prostate (RWPE-1) cells. Cleavage to EpICD-YFP was inhibited using DAPT, a $\gamma$-secretase inhibitor. Loading, $2 \mu \mathrm{g}$ DuCAP and PC3, $5 \mu \mathrm{g}$ Du145, LNCAP and RWPE-1. (D) EpCAM was visualised by immunofluorescence using either an anti-EpEx or an anti-EpICD antibody. Abbreviations: CTF, C-terminal fragment; EpICD, EpCAM intracellular domain; EpEx, EpCAM extracellular domain; FL, full length.

B). As our shRNA vector contained a GFP gene, we controlled uniform transduction efficiency of shRNA cells by measuring GFP expression using flow cytometry (Figure 5C). Next, we investigated the impact of EpCAM knockdown on cell proliferation using two different PCa cell lines. We found that neither transient EpCAM knockdown for $72 \mathrm{~h}$ nor stable EpCAM knockdown for a long time period (cells observed from passage $2-20=$ up to 10 weeks) had any measurable effect on cell proliferation (Figure 5D). In addition, inhibition of EpCAM signalling via RIP by inhibiting EpCAM cleavage using the chemical $\gamma$-secretase inhibitor DAPT had no inhibitory effect on prostate cell proliferation. For this experiment, we used three different PCa cell lines (Du145, DuCAP and PC3) and a non-cancerous prostate cell line (RWPE-1) with comparable results (Figure 5E). Finally, we tested whether overexpression of the signalling moiety EpICD mediates proliferative effects since EpICD was described to have the highest impact on cell proliferation (Maetzel et al, 2009; Chaves-Perez et al, 2012). Overexpression of EpICD-YFP had no influence on PCa cell proliferation or on proliferation of non-cancerous prostate cells (RWPE-1; Figure 5F). In summary EpCAM did not exert proliferative actions in PCa cells in vitro indicating that $\mathrm{PCa}$ cells are - in contrasts to other cellular cancer models - not dependent on high EpCAM expression levels for fast cell proliferation.

EpCAM is downregulated after chemotherapy with docetaxel. Treatment with the chemotherapeutic drug docetaxel is a standard therapy for patients with metastatic castration-resistant PCa. An acquired resistance to docetaxel has been associated with an EMT of cancer cells and subsequent dysregulation of cell surface proteins such as E-cadherin (Puhr et al, 2012). Therefore we anticipated EpCAM to be affected by EMT and analysed EpCAM expression in a set of PCa patients, who underwent neoadjuvant chemotherapy with docetaxel before radical prostatectomy and patients who did not got adjuvant treatment. Epithelial cell adhesion molecule was significantly lower in docetaxel-treated compared to untreated tumours (Figure 6A and B). In agreement with these in vivo data, EpCAM expression was found to be downregulated in docetaxel-resistant sublines of $\mathrm{PCa}$ cell lines (DU145 and PC3) at mRNA and protein level, respectively, (Figure 6C; Puhr et al, 2012). In summary our data reveal that EpCAM expression is suppressed by chemotherapeutic treatment, an effect that correlates with an EMT shift as previously shown (Puhr et al, 2012).

EpCAM mRNA and protein is affected by miR-200c and miR205. miR-200 family members are regulators that balance EMT and MET. Specifically, miR-200c and miR-205 enforce the epithelial phenotype by repression of the EMT-inducing transcription factors ZEB1 and ZEB2 (Gregory et al, 2008; Park et al, 2008). Docetaxel-resistant cell lines exert an EMT phenotype and, both, the expression of epithelial markers and miR-200/205 was significantly decreased (Puhr et al, 2012). Exposure of docetaxelresistant PCa cells to miR-200c and miR-205 reversed EMT, and led to re-expression of epithelial markers and re-sensitisation of the cells to docetaxel treatment (Puhr et al, 2012). As EpCAM represents an epithelial protein, we wondered whether its expression is influenced by miR-200c and miR-205. Single or combinatorial treatment of docetaxel-resistant $\mathrm{PCa}$ cells with 

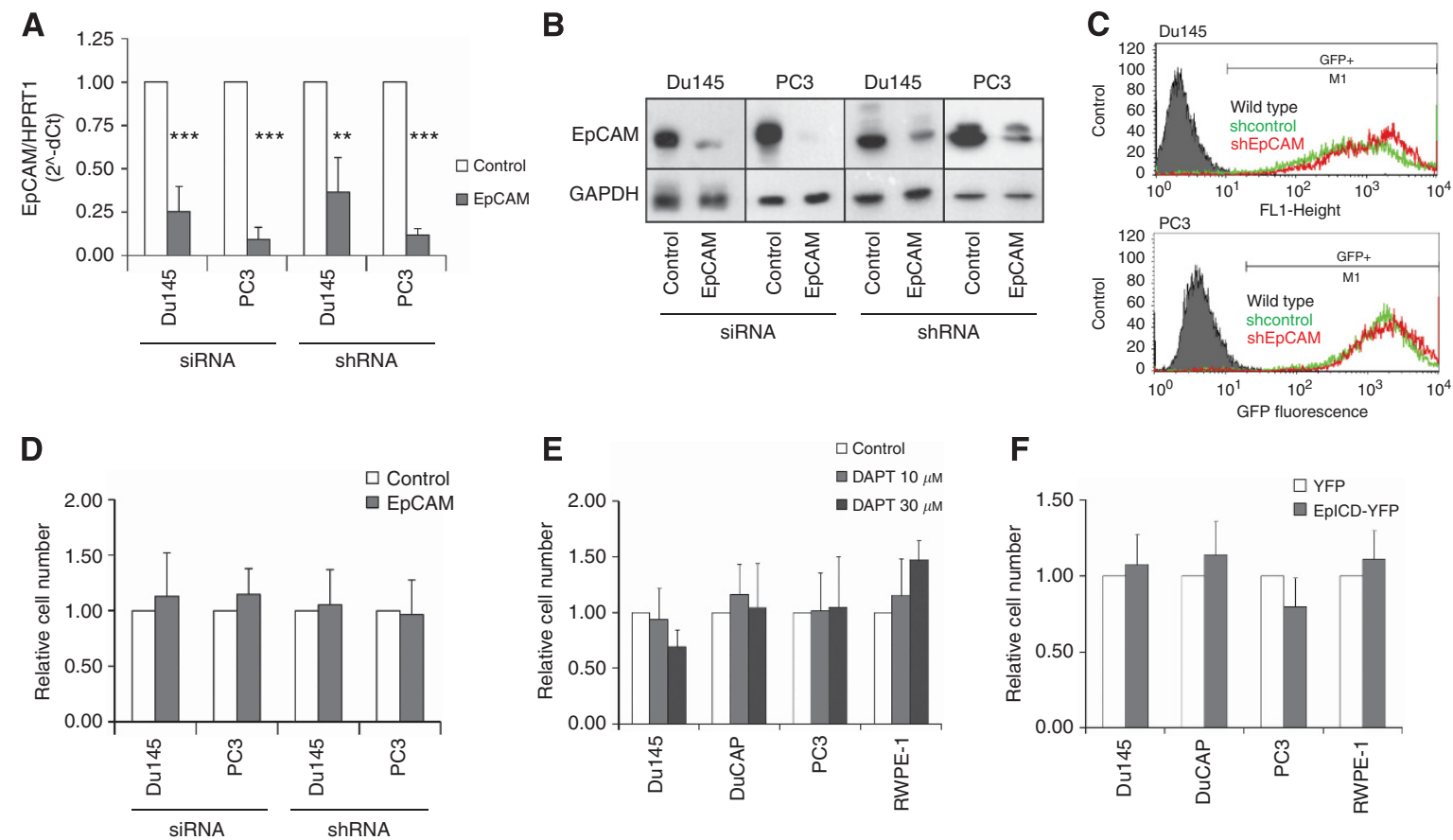

Figure 5. EpCAM has no proliferative effect on PCa cells in vitro. EpCAM knockdown was determined at mRNA level by qRT-PCR (A) and at protein level by immunoblot (B). Uniform transduction efficiency in shRNA cells was controlled by GFP expression (C). Neither transient EpCAM knockdown by siRNA for $72 \mathrm{~h}$ nor stable EpCAM knockdown by shRNA for a long time period (up to passage 20 after transduction) had any effect on PCa cell proliferation (D). Inhibition of EpCAM cleavage (first step of EpCAM signalling) by DAPT ( $\gamma$-secretase inhibitor, E) or overexpression of EpICD-YFP (YFP-stabilised intracellular domain of EpCAM, F) had no influence on prostate cell proliferation.

miR-200c and miR-205 resulted in re-expression of EpCAM mRNA and protein in chemoresistant cells. miR-200c/205 treated docetaxel-resistant cells reached comparable EpCAM levels as parental, docetaxel-sensitive cells (Figure 6D). In summary, our data demonstrate EpCAM downregulation following chemotherapeutic PCa treatment with docetaxel along with features of EMT. Re-expression of EpCAM was observed in the presence of miR200c and miR-205, two accepted inducers of MET.

\section{DISCUSSION}

In this manuscript, we present a detailed analysis for EpCAM expression in PCa. We thoroughly characterised EpCAM on mRNA and protein level and included both PCa tissues as well as frequently used PCa cell lines. In our comprehensive tissue study, we analysed non-cancerous prostate tissues and primary tumours of different grades and stages, as well as therapy-treated tumour specimen ( $>950$ samples in total). In summary, we prove that EpCAM mRNA and protein are overexpressed in PCa. In contrast to previous studies (Went et al, 2004; Benko et al, 2011; Ni et al, 2013), which were limited by sample size, individual patient cohorts, and selected methodologies (immunohistochemistry or expression analysis, only), our study combines data of independent patient cohorts (i.e., eight cohorts for PCa), applying several different methodologies (i.e., expression analysis on Affymetrix and Illumina platforms, qRT-PCR, immunoblot, immunohistochemistry, and flow cytometry), and was further complemented with functional data in cellular model systems. Thus, we consider our study free of methodological, statistical, or populationdependent bias.

Overexpression of EpCAM is more pronounced at protein level (on average four-fold) than at mRNA level (on average two-fold) in malignant compared to benign prostate tissues. This is a strong indicator that EpCAM levels are not only influenced by changes in gene expression, but also by modifications at the post-transcriptional and post-translational level. In this respect, glycosylation and endocytosis might play important roles in the regulation of cell surface expression of EpCAM (Munz et al, 2008; Hachmeister et al, 2013). Therefore, transcriptional mRNA-based data on EpCAM expression are likely to underestimate the amount of EpCAM overexpression in cell lines and tissues. Furthermore, our findings indicate that an increased EpCAM protein expression is an early event in PCa (present already in local low-grade cancer), which is further intensified in high-grade PCa tumours and PCa metastases.

Not only in several models of head and neck cancers (Maetzel et al, 2009; Chaves-Perez et al, 2012; Driemel et al, 2013), but also in breast (Martowicz et al, 2012), colorectal (Maaser and Borlak, 2008), and lung (Maaser and Borlak, 2008) cancers, EpCAM expression was reported to have a major impact on cell proliferation. Tumours with high EpCAM expression are considered to be highly proliferative and it was shown that EpCAM downregulation leads to a major reduction in cell proliferation in these tumour models (Osta et al, 2004; Maetzel et al, 2009; Chaves-Perez et al, 2012; Driemel et al, 2013). Although an inhibitory proliferative effect of EpCAM knockdown was recently described also for PCa cells (Ni et al, 2013), in our experiments we did not observe any effects on PCa cell proliferation upon EpCAM downregulation (long term or short term), overexpression of the intracellular signalling molecule EpICD, or blockage of EpCAM cleavage by chemical inhibitors, in vitro. Our findings may be supported by the fact that screened low-grade tumours, which are known to grow slowly and which are often considered to be clinically insignificant, display increased EpCAM levels despite a low proliferative capacity. Furthermore, we did not observe the presence of nuclear EpICD in the investigated cellular models (Figure 4D). As nuclear EpICD was described to be the main mediator of EpCAM-driven proliferation (Maetzel et al, 2009), the absence of nuclear EpICD in the investigated PCa cell lines 
A

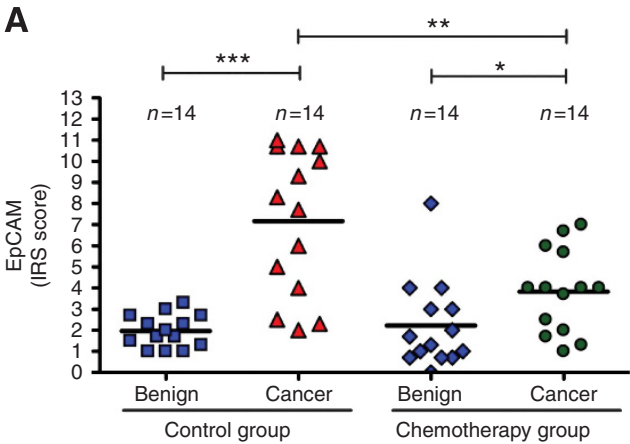

C
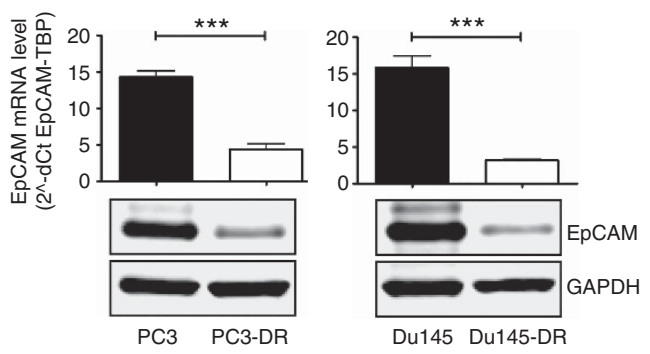
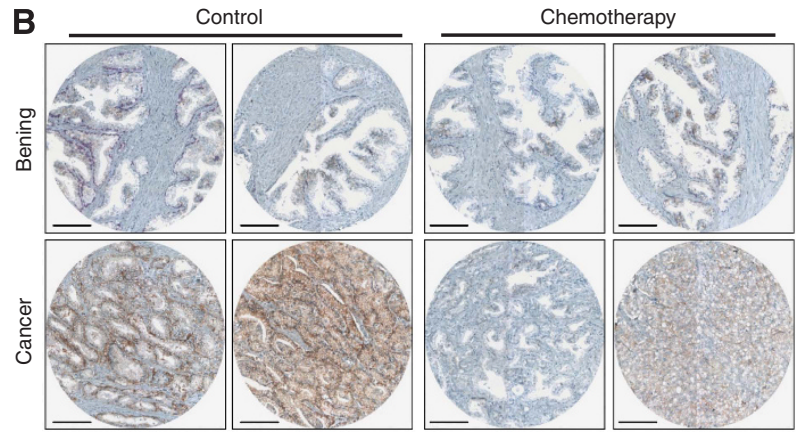

D

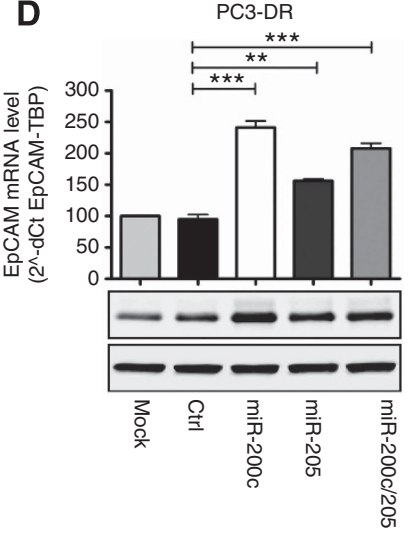

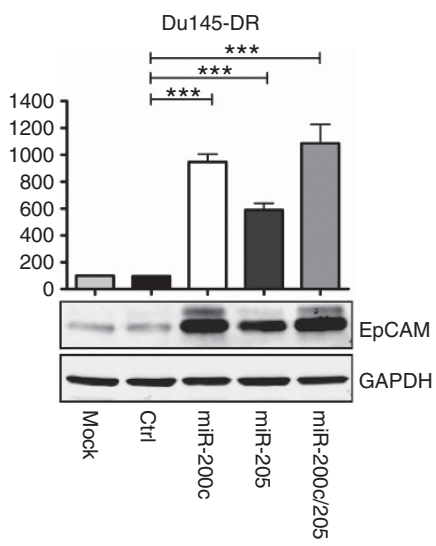

Figure 6. EpCAM expression is reduced in docetaxel-treated patients as well as in docetaxel-resistant cell lines and is a marker for an epithelial phenotype. (A and B) EpCAM protein expression is significantly reduced in prostate tissues of patients who received neoadjuvant chemotherapy with docetaxel before radical prostatectomy. Co-staining of EpCAM (brown) and p63 (blue, marker for basal cells) ensured correct discrimination between benign and cancer glands. (C) EpCAM mRNA and protein expression is reduced in docetaxel-resistant PC3-DR and Du-145-DR cells compared to parental cells. (D) EpCAM is a marker for an epithelial phenotype. Transfection of mature miR-200c and miR-205 leads to reexpression of EpCAM mRNA and protein in docetaxel-resistant cells, respectively. Semiquantitative immunohistochemistry analysis was performed applying quickscore criteria. Statistics were calculated using Mann-Whitney $U$ testing (A) or Student's t-testing $(\mathbf{C}$ and $\mathbf{D})$; ${ }^{\star} P<0.05$; ${ }^{\star \star} P<0.01$; $\star \star \star P<0.001$; bar, $100 \mu \mathrm{m}$. Abbreviation: IRS, immunoreactivity staining score.

represents a possible explanation for the absence of effect on cell proliferation. However, we did not experimentally investigate the influence of EpCAM blockage on cell proliferation in vivo so far. In other tumour entities, proliferative effects observed in vitro and in vivo, were, however, comparable (Maetzel et al, 2009; Martowicz et al, 2012; Driemel et al, 2013). Thus, despite the fact that EpCAM is overexpressed in PCa, in contrast to other tumour entities its cancer-associated functions, according to our experiments, seem not to be related to cellular proliferation.

Due to the fact that EPCAM is significantly increased in many tumour entities, EpCAM is already under investigation as a candidate protein for cancer therapies, including vaccination strategies (Mellstedt et al, 2000; Chaudry et al, 2007; Fournier and Schirrmacher, 2013), toxin-conjugated antibody fragments (Di Paolo et al, 2003; Stish et al, 2007), and monoclonal as well as bi-/tri-specific antibodies (Heideman et al, 2001; Riesenberg et al, 2001; Ammons et al, 2003). The trifunctional bispecific antibody catumaxomab (anti-CD3, anti-EpCAM) was already approved for treatment of EpCAM-positive malignant ascites (Seimetz et al, 2010). Thus, it is concluded that EpCAM shows high potential to be used as target for targeted and target-selective therapy in a variety of malignancies. However, the selection of the best treatment group in terms of indications as well as best treatment responsiveness still remains very challenging. This is also related to the fact that EpCAM levels are very heterogeneous and, thus, vary significantly depending on the context and tumour cell phenotype (Martowicz et al, 2012; Driemel et al, 2013). Mesenchymal cancer cells display no or only low levels of EpCAM, in contrast to epithelial cancer cells. Moreover, observed dynamic changes in
EpCAM expression were linked to a changing tumour cell microenvironment during cancer progression (Driemel et al, 2013). In addition, Thurm et al (2003) were able to demonstrate that first-line adjuvant chemotherapy resulted in a clonal selection of EpCAM-negative chemotherapy-resistant breast cancer cells and concluded that EpCAM-targeting is not a suitable approach for second-line therapies in breast cancer. On the other hand residual cells such as circulating and disseminating tumour cells (CTCs/ DTCs) might well decrease EpCAM expression transiently, but reinduce EpCAM expression when proliferation is required. This might for example occur in DTCs that have settled at a locoregional or distant site and start proliferating again. Accordingly, Jojovic et al, described a dynamic expression of EpCAM in human cancer cells after xenotransplantation in immunocompromised mice. In this study, EpCAM was strongly expressed in primary tumours and metastases comprised of $>30$ cells, while it was substantially reduced in small metastases ( $<30$ cells; Jojovic et al, 1998). In line with these findings, EpCAM is frequently reduced or missing in CTCs and DTCs (Gorges et al, 2012; Driemel et al, 2013). However, patients suffering from oesophageal cancers and bearing EpCAM-positive DTCs had the worst prognosis with very poor overall survival and the presence of lymph node metastases (Driemel et al, 2013).

In line with these observations, we observed a significantly reduced EpCAM expression after treatment with the chemotherapeutic drug docetaxel in PCa patients as well as in docetaxelresistant cell lines, in vitro. Due to significant benefits concerning survival, reduced pain, and enhanced quality of life, docetaxel is state of the art treatment for different types of cancer. 
Unfortunately, many patients do not respond to docetaxel or acquire a drug resistance during treatment. In a previous publication, we linked an acquired docetaxel insensitivity with EMT and to a reduced expression of miRNAs miR-205 and miR-200c, which led to a clonal selection of docetaxelresistant PCa cells, characterised by a mesenchymal phenotype (Puhr et al, 2012). It is well known that both miRNAs enforce the epithelial phenotype by repression of the transcription factors ZEB1 and ZEB2, and are thus considered inducers of MET (Gregory et al, 2008; Park et al, 2008). Strikingly, we were able to demonstrate that single or combined re-expression of miR-200c and miR-205 resulted in restored EpCAM levels and in an epithelial cell phenotype. In line with our findings are observation by Vannier et al (2013), who demonstrated a ZEB1-dependent repression of EpCAM in human pancreatic and breast cancer cell lines, which was mediated through direct binding of ZEB1 to the EpCAM promoter.

In addition to possible application as a therapy target, EpCAM is widely used as a target protein for isolation of CTCs; (Allard et al, 2004; Cristofanilli et al, 2004; Nagrath et al, 2007; Riethdorf et al, 2008). However, as a consequence of recent findings, we and others (Gorges et al, 2012; Driemel et al, 2013) have major concerns using EpCAM as a marker for CTC isolation. It is an accepted fact that CTCs undergo EMT in order to acquire a migratory phenotype needed to detach from their tissues of origin. Thus, CTCs are often characterised by a reduced EpCAM expression, as was shown by Gorges and colleagues, who identified EpCAM-negative CTC subpopulations in murine breast cancer xenograft models (MDAMB-231, MDA-MB-468 and KPL-4; Gorges et al, 2012; Driemel et al, 2013). Therefore, assays using EpCAM as a target for isolation of CTCs may underestimate the total number of CTCs in the circulation and thereby enrich for cells, which did not undergo a pronounced mesenchymal switch (Konigsberg et al, 2011).

In conclusion, our data confirm that EpCAM overexpression is an early event in PCa carcinogenesis. Thus, EpCAM needs to have major cancer-promoting functions in this cancer entity although our data showed no effect on proliferation. Additional experimental data are required to get more insights on specific EpCAM functions on other hallmarks of cancer, for example, adhesion and invasion, and establish a potential of EpCAM or EpCAM-mediated targeting therapies for PCa treatment.

\section{ACKNOWLEDGEMENTS}

We thank Georg Schäfer, Karin Unterberger and Irma Sottsas for scientific and technical assistance. We acknowledge financial support from the Austrian Science Fund FWF (Grant J3201 to PM, and Grant P 25639-B19 to MP), the Friedrich-Baur-Stiftung Munich (Grant 39/12 to PM), the intramural funding programme of the Medical University of Innsbruck (MUI-START Grant 2010012007 to MP), and the Deutsche Krebshilfe (109080 to OG).

\section{CONFLICT OF INTEREST}

PM is currently working in a DAAD fellowship at Roche Diagnostics GmbH. The work presented here is independent of the fellowship or any work related to Roche Diagnostics GmbH.

\section{REFERENCES}

Allard WJ, Matera J, Miller MC, Repollet M, Connelly MC, Rao C, Tibbe AG, Uhr JW, Terstappen LW (2004) Tumor cells circulate in the peripheral blood of all major carcinomas but not in healthy subjects or patients with nonmalignant diseases. Clin Cancer Res 10: 6897-6904.
Ammons WS, Bauer RJ, Horwitz AH, Chen ZJ, Bautista E, Ruan HH, Abramova M, Scott KR, Dedrick RL (2003) In vitro and in vivo pharmacology and pharmacokinetics of a human engineered monoclonal antibody to epithelial cell adhesion molecule. Neoplasia 5: 146-154.

Baeuerle PA, Gires O (2007) EpCAM (CD326) finding its role in cancer. Br J Cancer 96: 417-423.

Balzar M, Prins FA, Bakker HA, Fleuren GJ, Warnaar SO, Litvinov SV (1999) The structural analysis of adhesions mediated by Ep-CAM. Exp Cell Res 246: $108-121$.

Bartsch G, Horninger W, Klocker H, Pelzer A, Bektic J, Oberaigner W, Schennach H, Schafer G, Frauscher F, Boniol M, Severi G, Robertson C, Boyle P (2008) Tyrol Prostate Cancer Demonstration Project: early detection, treatment, outcome, incidence and mortality. BJU Int 101: 809-816.

Bello D, Webber MM, Kleinman HK, Wartinger DD, Rhim JS (1997) Androgen responsive adult human prostatic epithelial cell lines immortalized by human papillomavirus 18. Carcinogenesis 18: 1215-1223.

Benko G, Spajic B, Kruslin B, Tomas D (2011) Impact of the EpCAM expression on biochemical recurrence-free survival in clinically localized prostate cancer. Urol Oncol 31(4): 468-474.

Brock R, Hamelers IH, Jovin TM (1999) Comparison of fixation protocols for adherent cultured cells applied to a GFP fusion protein of the epidermal growth factor receptor. Cytometry 35: 353-362.

Chaudry MA, Sales K, Ruf P, Lindhofer H, Winslet MC (2007) EpCAM an immunotherapeutic target for gastrointestinal malignancy: current experience and future challenges. $\mathrm{Br} J$ Cancer 96: 1013-1019.

Chaves-Perez A, Mack B, Maetzel D, Kremling H, Eggert C, Harreus U, Gires O (2012) EpCAM regulates cell cycle progression via control of cyclin D1 expression. Oncogene 32(5): 641-650.

Cristofanilli M, Budd GT, Ellis MJ, Stopeck A, Matera J, Miller MC, Reuben JM, Doyle GV, Allard WJ, Terstappen LW, Hayes DF (2004) Circulating tumor cells, disease progression, and survival in metastatic breast cancer. N Engl J Med 351: 781-791.

Denzel S, Maetzel D, Mack B, Eggert C, Barr G, Gires O (2009) Initial activation of EpCAM cleavage via cell-to-cell contact. BMC Cancer 9: 402.

Detre S, Jotti GS, Dowsett M (1995) A "quickscore" method for immunohistochemical semiquantitation: validation for oestrogen receptor in breast carcinomas. J Clin Pathol 48: 876-878.

Di Paolo C, Willuda J, Kubetzko S, Lauffer I, Tschudi D, Waibel R, Pluckthun A, Stahel RA, Zangemeister-Wittke U (2003) A recombinant immunotoxin derived from a humanized epithelial cell adhesion molecule-specific singlechain antibody fragment has potent and selective antitumor activity. Clin Cancer Res 9: 2837-2848.

Driemel C, Kremling H, Schumacher S, Will D, Wolters J, Lindenlauf N, Mack B, Baldus SA, Hoya V, Pietsch JM, Panagiotidou P, Raba K, Vay C, Vallböhmer D, Harréus U, Knoefel WT, Stoecklein NH, Gires O (2013) Context-dependent adaption of EpCAM expression in early systemic esophageal cancer. Oncogene; e-pub ahead of print 21 October 2013; doi:10.1038/onc.2013.441.

Fournier P, Schirrmacher V (2013) Bispecific antibodies and trispecific immunocytokines for targeting the immune system against cancer preparing for the future. BioDrugs 27: 35-53.

Gastl G, Spizzo G, Obrist P, Dunser M, Mikuz G (2000) Ep-CAM overexpression in breast cancer as a predictor of survival. Lancet 356: 1981-1982.

Gorges TM, Tinhofer I, Drosch M, Roese L, Zollner TM, Krahn T, von Ahsen O (2012) Circulating tumour cells escape from EpCAM-based detection due to epithelial-to-mesenchymal transition. BMC Cancer 12: 178.

Gregory PA, Bert AG, Paterson EL, Barry SC, Tsykin A, Farshid G, Vadas MA, Khew-Goodall Y, Goodall GJ (2008) The miR-200 family and miR-205 regulate epithelial to mesenchymal transition by targeting ZEB1 and SIP1. Nat Cell Biol 10: 593-601.

Hachmeister M, Bobowski KD, Hogl S, Dislich B, Fukumori A, Eggert C, Mack B, Kremling H, Sarrach S, Coscia F, Zimmermann W, Steiner H, Lichtenthaler SF, Gires O (2013) Regulated Intramembrane Proteolysis and Degradation of Murine Epithelial Cell Adhesion Molecule mEpCAM. PLoS One 8: e71836.

Hanahan D, Weinberg RA (2000) The hallmarks of cancer. Cell 100: 57-70.

Heideman DAM, Snijders PJF, Craanen ME, Bloemena E, Meijer C, Meuwissen SGM, van Beusechem VW, Pinedo HM, Curiel DT, Haisma HJ, Gerritsen WR (2001) Selective gene delivery toward gastric and esophageal adenocarcinoma cells via EpCAM-targeted adenoviral vectors. Cancer Gene Ther 8: 342-351.

Jojovic M, Adam E, Zangemeister-Wittke U, Schumacher U (1998) Epithelial glycoprotein-2 expression is subject to regulatory processes in 
epithelial-mesenchymal transitions during metastases: an investigation of human cancers transplanted into severe combined immunodeficient mice. Histochem J 30: 723-729.

Kogan I, Goldfinger N, Milyavsky M, Cohen M, Shats I, Dobler G, Klocker H, Wasylyk B, Voller M, Aalders T, Schalken JA, Oren M, Rotter V (2006) hTERT-immortalized prostate epithelial and stromal-derived cells: an authentic in vitro model for differentiation and carcinogenesis. Cancer Res 66: 3531-3540.

Konigsberg R, Obermayr E, Bises G, Pfeiler G, Gneist M, Wrba F, de Santis M, Zeillinger R, Hudec M, Dittrich C (2011) Detection of EpCAM positive and negative circulating tumor cells in metastatic breast cancer patients. Acta Oncol 50: 700-710.

Kuner R, Falth M, Pressinotti NC, Brase JC, Puig SB, Metzger J, Gade S, Schafer G, Bartsch G, Steiner E, Klocker H, Sultmann H (2012) The maternal embryonic leucine zipper kinase (MELK) is upregulated in high-grade prostate cancer. J Mol Med (Berl) 91: 237-248.

Maaser K, Borlak J (2008) A genome-wide expression analysis identifies a network of EpCAM-induced cell cycle regulators. Br J Cancer 99: 1635-1643.

Maetzel D, Denzel S, Mack B, Canis M, Went P, Benk M, Kieu C, Papior P, Baeuerle PA, Munz M, Gires O (2009) Nuclear signalling by tumourassociated antigen EpCAM. Nat Cell Biol 11: 162-171.

Martowicz A, Spizzo G, Gastl G, Untergasser G (2012) Phenotype-dependent effects of EpCAM expression on growth and invasion of human breast cancer cell lines. BMC Cancer 12: 501.

Massoner P, Kugler KG, Unterberger K, Kuner R, Mueller LA, Falth M, Schafer G, Seifarth C, Ecker S, Verdorfer I, Graber A, Sultmann H, Klocker H (2013) Characterization of transcriptional changes in ERG rearrangement-positive prostate cancer identifies the regulation of metabolic sensors such as neuropeptide Y. PLoS One 8: e55207.

Mellstedt H, Fagerberg J, Frodin JE, Hjelm-Skog AL, Liljefors M, Markovic K, Mosolits S, Ragnhammar P (2000) Ga733/EpCAM as a target for passive and active specific immunotherapy in patients with colorectal carcinoma. Ann N Y Acad Sci 910: 254-262.

Moldenhauer G, Momburg F, Moller P, Schwartz R, Hammerling GJ (1987) Epithelium-specific surface glycoprotein of $\mathrm{Mr} 34,000$ is a widely distributed human carcinoma marker. Br J Cancer 56: 714-721.

Munz M, Fellinger K, Hofmann T, Schmitt B, Gires O (2008) Glycosylation is crucial for stability of tumour and cancer stem cell antigen EpCAM. Front Biosci 13: 5195-5201.

Munz M, Kieu C, Mack B, Schmitt B, Zeidler R, Gires O (2004) The carcinoma-associated antigen EpCAM upregulates c-myc and induces cell proliferation. Oncogene 23: 5748-5758.

Nagrath S, Sequist LV, Maheswaran S, Bell DW, Irimia D, Ulkus L, Smith MR, Kwak EL, Digumarthy S, Muzikansky A, Ryan P, Balis UJ, Tompkins RG, Haber DA, Toner M (2007) Isolation of rare circulating tumour cells in cancer patients by microchip technology. Nature 450: 1235-1239.

Ni J, Cozzi P, Hao J, Beretov J, Chang L, Duan W, Shigdar S, Delprado W, Graham P, Bucci J, Kearsley J, Li Y (2013) Epithelial cell adhesion molecule (EpCAM) is associated with prostate cancer metastasis and chemo/radioresistance via the PI3K/Akt/mTOR signaling pathway. Int J Biochem Cell Biol 45: 2736-2748.

Osta WA, Chen Y, Mikhitarian K, Mitas M, Salem M, Hannun YA, Cole DJ, Gillanders WE (2004) EpCAM is overexpressed in breast cancer and is a potential target for breast cancer gene therapy. Cancer Res 64: 5818-5824.

Park SM, Gaur AB, Lengyel E, Peter ME (2008) The miR-200 family determines the epithelial phenotype of cancer cells by targeting the E-cadherin repressors ZEB1 and ZEB2. Genes Dev 22: 894-907.

Piyathilake CJ, Frost AR, Weiss H, Manne U, Heimburger DC, Grizzle WE (2000) The expression of Ep-CAM (17-1A) in squamous cell cancers of the lung. Hum Pathol 31: 482-487.

Ploner C, Rainer J, Niederegger H, Eduardoff M, Villunger A, Geley S, Kofler R (2008) The BCL2 rheostat in glucocorticoid-induced apoptosis of acute lymphoblastic leukemia. Leukemia 22: 370-377.
Puhr M, Hoefer J, Schafer G, Erb HH, Oh SJ, Klocker H, Heidegger I, Neuwirt H, Culig Z (2012) Epithelial-to-mesenchymal transition leads to docetaxel resistance in prostate cancer and is mediated by reduced expression of miR-200c and miR-205. Am J Pathol 181: 2188-2201.

Rhodes DR, Yu J, Shanker K, Deshpande N, Varambally R, Ghosh D, Barrette T, Pandey A, Chinnaiyan AM (2004) ONCOMINE: a cancer microarray database and integrated data-mining platform. Neoplasia 6: 1-6.

Riesenberg R, Buchner A, Pohla H, Lindhofer H (2001) Lysis of prostate carcinoma cells by trifunctional bispecific antibodies (alpha EpCAM x alpha CD3). J Histochem Cytochem 49: 911-917.

Riethdorf S, Wikman H, Pantel K (2008) Review: biological relevance of disseminated tumor cells in cancer patients. Int J Cancer 123: 1991-2006.

Sastre M, Steiner H, Fuchs K, Capell A, Multhaup G, Condron MM, Teplow DB, Haass C (2001) Presenilin dependent gamma-secretase processing of beta-amyloid precursor protein at a site corresponding to the S3 cleavage of Notch. EMBO Rep 2: 835-841.

Seimetz D, Lindhofer H, Bokemeyer C (2010) Development and approval of the trifunctional antibody catumaxomab (anti-EpCAM x anti-CD3) as a targeted cancer immunotherapy. Cancer Treat Rev 36: 458-467.

Stish BJ, Chen H, Shu Y, Panoskaltsis-Mortari A, Vallera DA (2007) Increasing anticarcinoma activity of an anti-erbB2 recombinant immunotoxin by the addition of an anti-EpCAM sFv. Clin Cancer Res 13: 3058-3067.

Strnad J, Hamilton AE, Beavers LS, Gamboa GC, Apelgren LD, Taber LD, Sportsman JR, Bumol TF, Sharp JD, Gadski RA (1989) Molecular cloning and characterization of a human adenocarcinoma/epithelial cell surface antigen complementary DNA. Cancer Res 49: 314-317.

Thurm H, Ebel S, Kentenich C, Hemsen A, Riethdorf S, Coith C, Wallwiener D, Braun S, Oberhoff C, Janicke F, Pantel K (2003) Rare expression of epithelial cell adhesion molecule on residual micrometastatic breast cancer cells after adjuvant chemotherapy. Clin Cancer Res 9: 2598-2604.

Tomlins SA, Rhodes DR, Perner S, Dhanasekaran SM, Mehra R, Sun XW, Varambally S, Cao X, Tchinda J, Kuefer R, Lee C, Montie JE, Shah RB, Pienta KJ, Rubin MA, Chinnaiyan AM (2005) Recurrent fusion of TMPRSS2 and ETS transcription factor genes in prostate cancer. Science 310: 644-648.

Trzpis M, McLaughlin PM, de Leij LM, Harmsen MC (2007) Epithelial cell adhesion molecule: more than a carcinoma marker and adhesion molecule. Am J Pathol 171: 386-395.

van der Gun BT, Melchers LJ, Ruiters MH, de Leij LF, McLaughlin PM, Rots MG (2011) EpCAM in carcinogenesis: the good, the bad or the ugly. Carcinogenesis 31: 1913-1921.

Vannier C, Mock K, Brabletz T, Driever W (2013) Zeb1 regulates E-cadherin and Epcam (epithelial cell adhesion molecule) expression to control cell behavior in early zebrafish development. J Biol Chem 288: 18643-18659.

Went P, Vasei M, Bubendorf L, Terracciano L, Tornillo L, Riede U, Kononen J, Simon R, Sauter G, Baeuerle PA (2006) Frequent high-level expression of the immunotherapeutic target Ep-CAM in colon, stomach, prostate and lung cancers. Br J Cancer 94: 128-135.

Went PT, Lugli A, Meier S, Bundi M, Mirlacher M, Sauter G, Dirnhofer S (2004) Frequent EpCam protein expression in human carcinomas. Hum Pathol 35: 122-128.

Wu CJ, Mannan P, Lu M, Udey MC (2013) Epithelial cell adhesion molecule (EpCAM) regulates claudin dynamics and tight junctions. J Biol Chem 288: $12253-12268$.

This work is published under the standard license to publish agreement. After 12 months the work will become freely available and the license terms will switch to a Creative Commons AttributionNonCommercial-Share Alike 3.0 Unported License. 